\title{
Egypt Wedding Tourism destinations: A new Tourism Demand Motivator, The case of El Gouna
}

\author{
Dalia F. Amara \\ Lecturer - Hotels and Tourism Department \\ Arab Academy for Science, Technology and Maritime Transport, Egypt
}

\begin{abstract}
With the need to increase tourism demand by focusing on alternative forms of tourism, wedding based tourism has gained significant attention in recent years, providing new tourism opportunities in accordance with such demand. Tourism motivations are important factors in understanding tourist behavior in relation to destination's choice, especially for the wedding market. However, very little research has been conducted regarding the travel behavior of wedding tourism. The purpose of the study was to describe the various travel motivations of wedding tourism to oneof the more attractive tourism destinations in Egypt with its distinctive characteristics, which is El Gouna, in Hurghada, Red Sea. The study adopts a mixed method based on an exploratory quantitative and qualitative approaches for data collection.It embracesthe demand-side perspective in order to deepen the knowledge about the motivation that drives people to celebrate their wedding outside their hometown. Findings revealed that wedding tourists are primarily attracted by the destination's attributes such as the "sea, sun and sand" in the case of El Gouna considered a summer destination, which forms part of anattractive experience or adventure. And that marketing and promoting El Gouna as a wedding destination is still as its first stages. Thus, it was suggested that in order to encourage wedding tourism, increasing marketing and promotion efforts could help to be an effective tool.
\end{abstract}

Keywords: wedding tourism, motivations, perceptions, attraction attributes, Egypt

\section{Introduction}

Wedding tourism is becoming a prevalent part of the tourism industry with "away wedding" growing rapidly (Travel Trends Today, 2013; Travel Daily UK,2014). The success of wedding tourism continues to be propelled by a variety of emotional and economic factors. In almost every culture, the wedding is a significant life event which calls for celebration in a deeply personal and memorable way (Breg, 2013). Due to socio-economic changes of the modern society, such as traditional weddings which are expensive in terms of costs, decreased cost and improved frequency of international flights, cost savings arising from the smaller number of people willing to participate in the ceremony, and the possibility that couples can combine wedding with 
honeymoon (Schumann \&Amando, 2010), wedding travel is now considered as being an important part of the tourism industry.

Wedding-based tourism can be defined as tourist flows arising from participation in weddings that are held at a different location from where the bride and groom, or just one of them, live (Daniels \&Loveless, 2007). Another type of wedding flow is when the event takes place in the bride's or groom's home town and guests arrive from other places. The market is made up of marriages (of the first-time, second or more), same-sex marriages, commitment ceremonies and renewal of vows (Major \& McLeay ,2010). Destination weddings can be more exotic, warm, and unique. They enable couples to experience different rituals and cultures, and sometimes to escape any latent social and family obligations.

Wedding tourism is booming, and several destinations (such as Las Vegas, Hawaii, the Caribbean, Mexico, Fiji, Jamaica, Europe, etc.) are currently positioning themselves in this lucrative market (Daniels \& Loveless, 2007).The growing numbers of wedding tourists in these destinations confirms the importance of this emerging market segment worldwide. Since 2007, the overall growth in this market was estimated to be approximately ten percent annually, with an expectation for even higher growth rates in the period to follow (Travel Trends Today ,2016).

\section{Research Aim}

The study aims to analyze and interpret different travel motivations of wedding tourismidentified as an important niche market to one of the more attractive tourism destinations in Egypt, which is El Gouna. Itexplores the development of this relatively new and emerging trend of tourism, focusing on the demand-side perspective.

\section{Tourist Travel Motivators}

Travel motivations create a desire in an individual to travel and to choose a particular exotic destination to explore and discover. People travel for the reason that they are pushed by psychological and pulled by external forces of the destination attributes (March \& Woodside,2005). The push-pull approach remains the most widely applied for explaining motivations, given its simplicity and intuitive approach (Klenosky, 2002). Tourists are pushed by their biogenic and emotional needs to travel and pulled by destination attributes (Yoon \&Uysal, 2005). This process is moderated by factors such as involvement, imagery and emotions (White \& Thompson, 2009). The push-pull approach is often used for market segmentation purposes with the aim of profiling visitors. Similarly, the influence of demographic and travelling characteristics on motivations is thoroughly investigated (Kim \&Prideaux, 2005). Given that the motivations of the pleasure travel market are well researched; authors are exploring the motivations of other prominent niche markets such as wedding tourism.

Although, Egypt suffered since 2011 from political and economic instability, indeed it is still seen as one of the most motivating destinations that satisfies tourists' socio-psychological needs. El Gouna caters to satisfy the motive to demonstrate the sign of affection and belongingness in the case of wedding. Combined with these push factors, pull factors such as destination location, and its attributes also influence traveler's choice. This include both tangible and intangible elements like beaches, rivers, landscape, biodiversity, the 3'S the "sea, sun and sand" and others (Prayag\& 
Ryan,2011). Wedding ceremonies are highly dependent on facilities provision which determine the choice of any destination to be 'the place' to get married. These facilities range from wedding location, facilities/amenities, cost satisfaction, quality services and good accommodation (Awaritefe,2004). Tourists' are further pulled by factors such as destination marketing and promotion. Promoting wedding tourism needs to communicate to potential visitors, various wedding tourism products and services offered by a destination along with its most attractive features, which help in differentiating destinations' images and therefore influence tourist decision for his destination choice.

\section{Wedding Tourism in Egypt - The case of El Gouna}

Weddings have become a commodity, providing opportunities for each host destination to market itself as a place where a special life event can be commemorated in an unforgettable way (Boden, 2001). Cultural and social influences play a big role in characterizing the weddings and the honeymoon market in Egypt, where weddings at home are preferred and honeymooners take a short overseas trip or short haul honeymoons. It's about price and time. There are a variety of factors affecting destination choice, with aspects of nature and scenery being the most influential (Kim \& Agrusa, 2005). Egypt exerts every effort possible to diversify its modes of tourism and to introduce new types of tourism that cater to the taste of the various tourists. With the continuous success of this new tourism market, particular concern and importance was given to beach wedding destinations in Egypt.

El Gouna is one of the most attractive beach destinations in Egypt, located 25 kilometers north of Hurghada, on the Red Sea, southern Egypt, a 4-hour flight from Europe's major capitals and 30 minutes' flight from Cairo. The town is easily accessed from Europe via Hurghada International airport; its location offers good access to Egypt's historical and archeological treasures. The ancient temples of Luxor and Aswan are only a bus away. Day and overnight trips to Luxor, Aswan, Cairo, and Sinai could be arranged from El Gouna. It is a distinctive brand destination offering many things to its visitors to enjoy including sun, sea and sand, as well as other culture and entertainment attractions.

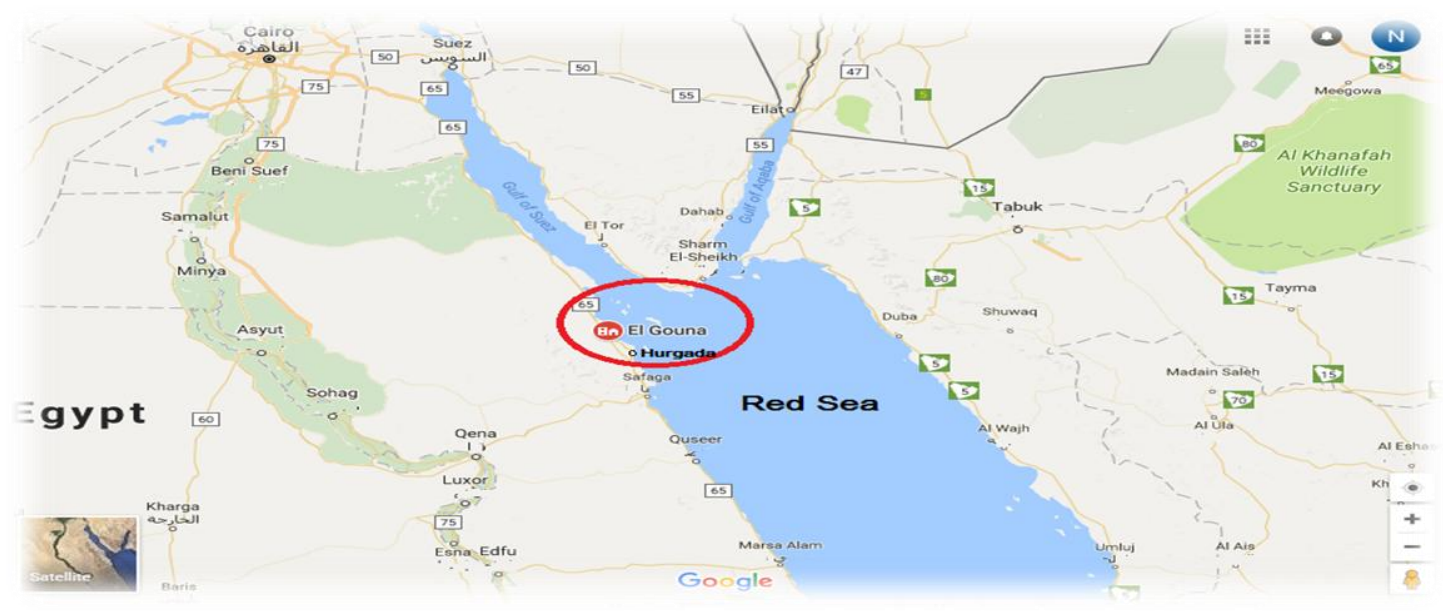

Figure 1: El Gouna Map- RedSea-Egypt

Source:https://www.google.com.eg/maps/search/el+gouna+map/ 


\section{Research Methodology}

The study adopts a mixed method based on exploratory quantitative and qualitative approaches for data collection. A quantitative questionnaire was designed based on motivations for wedding tourism. The questionnaire aimed at investigating the motives behind being interested in and/or participating in wedding tourism as a travel motivator. The total lodging facilities at El Gouna is 129 hotels. Only 5 hotels are categorized as five stars' hotels (www.hotels.com/ElGouna/Hotel). The survey involved tourists residing in selected 4 of these five stars' hotels in El Gouna including; Mővenpick Resort and Spa, La Maison Bleue, Steignberger Golf Resort and Sheraton Miramar Resort. A purposive sample of 165 tourists was selected for this study out of which $(n=$ 151) questionnaires were retained and 14 were discarded as not sufficiently complete for analysis. The sample size was considered relatively small to El Gouna 's visitors' population, as the survey was conducted in May, which is an off season at El Gouna for the domestic tourist market, and moreover, according to the latest figures from state statistics agency CAPMAS (July, 2017) tourist arrivals to Egypt declined by 51.7 percent year-on-year in May, with just 431,800 visitors compared to 894,600 in the same month last year. Much of the decline in arrivals is also, due to the absence of Russian and other Eastern European tourists, formerly the largest group of visitors to Egypt. With a Russian flight ban still in place, the number of Russian tourists fell 61.3 percent compared to already weak figures in the same month last year. In addition to the continuous tourists' attacks incidents on Hurghada beaches by the extremist militia associated with the issued travel warnings to the Red Sea and to Hurghada in particular.

Distribution of self-completion questionnaires was carried, over five consecutive days, at different time of the day. Respondents were approached and informed about the purpose of the survey in advance of being given the questionnaire. Respondents younger than age 15 were automatically excluded. With an attempt to apply a random sample, not only couples were targeted to participate in the survey, but tourists who were in El Gouna for the purpose of getting married or coming to attend a wedding, and those who had already got married in El Gouna or elsewhere and were on honeymoon, with the purpose of obtaining different views. The questionnaire was identical for Egyptians and non-Egyptians, and available in English and Arabic. The questionnaires consisted of 16 questions comprising of multiple-choice and open-ended set.The first part of the questionnaire was informing about tourists' demographics, and the second part was investigating the dimensions of travel motivation factors that attract tourists to come to El Gouna or choose it as a wedding destination. The questions on motives had a 5-point Likert type scale, 1 being' not very important', and 5 being 'very important'.

Furthermore, unstructured interviews were carried out through onsite visits at the selected hotels visited, with guests who had decided to visit El Gouna destination. These interviews aimed at investigating the main motivations for choosing El Gouna as a tourist destination generally, and/or for celebrating their wedding specifically.

\section{Results and Discussion}

Based on the aim of this research and the review of the literature on the various motivation factors that influence travel decision, the following sections discusses the results of the study as to what is prevailing in identifying El Gouna as "a wedding destination".Univariate and multivariate 
statistics were used to analyze the data. Descriptive statistics were firstly used to determine the frequency distribution of the demographic profiles, motives and opinions of the survey's participants toward the wedding-based tourism. An analysis of variance was then used to determine whether the survey's participants have traveled before to participate in a wedding or not. And if the number of times of participation in such ideas, affected motives and opinions.

\subsection{Quantitative Analysis}

The demographics of the participants enables a better understanding of the type of tourists that are attracted or would have been attracted to El Gouna as a wedding destination. As seen in table 1 below, most of the respondents $63.3 \%$ were Egyptians, taking into consideration the importance given to study the domestic tourism market for such type of tourism, followed by British tourists $17.0 \%$ and in third position, El Gouna's biggest holiday generating country is France, which represents $9.5 \%$ of the respondents. From this data, it is seen that regardless the cost of flying or of road transport from the capital or other big Egyptian cities, Egyptians have a great potential to plan to celebrate and/or participate in weddings at El Gouna. Honeymoon tourism is bearing up and continues to be a high-yield market for many Egyptian tourism destinations such as El Gouna.

$\begin{array}{llll} & & \text { Frequency } & \text { Percent } \\ & \text { Egypt } & 93 & 63.3 \\ \text { Great Britain } & 25 & 17.0 \\ & \text { France } & 17 & 9.5 \\ \text { VALID } & \text { Italy } & 11 & 7.5 \\ & \text { Others } & 5 & 2.7 \\ & \text { TOTAL } & 151 & 100.0\end{array}$

Table1. Place of Residence of El Gouna wedding destination participants ( $\mathrm{n}=151$ )

As for the purpose of visit, results showed that the majority of respondents (66.2\%) came to El Gouna for honeymoon purpose. While a great demand (28.5\%) was for beach-based holiday, and $(4.0 \%)$ of the respondents were visiting El Gouna for attending weddings and special parties, and finally, $(1.3 \%)$ were related to other purposes of visit (table 2). The figures revealed that El Gouna being a beach-based holiday destination, its visitors are primarily attracted by the destination's attributes, the "sea, sun and sand", and consequently it is preferred by honeymooners and people who are looking to celebrate their weddings at a unique and untraditional place.

$\begin{array}{lll} & \text { Frequency } & \text { Percent } \\ \text { Beach-based holiday } & 43 & 28.5 \\ \text { Honeymoon } & 100 & 66.2 \\ \text { Attending wedding/ parties } & 6 & 4.0 \\ \text { Other purposes } & 2 & 1.3 \\ \text { Total } & 151 & 100.0\end{array}$

Table 2: Purpose of visit $(n=151)$ 
Table 3 reports the demographic profiles of the participants. The survey consists of both individual men, ladies and mixed groups, in addition to couples. Most of survey participants were female $(57 \%)$ and $(43 \%)$ were male. The largest percentage of the participants were between 21 and 30 years old $(47.7 \%)$ with $(24.2 \%)$ between 31 and 40 , and the older age group (12.1\%) mainly visiting for relaxation. With regards to the participant's employment status, the survey registered a majority of employees (75.2\%), a small proportion of self-employed (10.7\%) and housewives $(6.7 \%)$. Only $(4 \%)$ of the respondents had participated 5 to 7 times in wedding tourism before, while $(66.2 \%)$ of respondents were mainly taking part for the first time.

A frequency distribution of the motivations behind those participating in weddings held in El Gouna was carried out (Table 4). The respondents gave high importance to having fun with mean value (4.74), celebrating the wedding with the bride and groom (4.46), and to experiencing the atmosphere (4.26) as major reasons for taking part in the wedding. Also, the motives of eating and drinking having a mean score (2.89) and learning new things about the place (3.23) as less important.

$\begin{array}{lll}\text { Characteristics } & & \text { El Gouna }(n=151) \\ \text { Gender } & \text { Male } & 65(43.0 \%) \\ & & 86(57.0 \%) \\ \text { Age } & \text { Up to } 20 & 11(7.4 \%) \\ 21-30 & 71(47.7 \%) \\ 31-40 & 36(24.2 \%) \\ & 41-50 & 13(8.75 \%) \\ & 51-60 \text { and over } & 18(12.1 \%) \\ \text { Occupation } & \text { Employee } & 112(75.2 \%) \\ & \text { Retired } & 4(2.7 \%) \\ & \text { Housewife } & 10(6.7 \%) \\ & \text { Self employed } & 16(10.7 \%) \\ \text { Student } & 3(2.0 \%) \\ \text { Unemployed } & 4(2.7 \%) \\ \text { participating } & & \\ \text { in wedding Tourism } & \text { First time } & 100(66.2 \%) \\ & 2-4 & 43(28.5 \%) \\ & & 6(4.0 \%) \\ & 5-7 & 2(1.3 \%) \\ & & \end{array}$

$\mathrm{P}<0.05$

Table 3. Profile of El Gouna wedding destination participants 


\begin{tabular}{ccc}
\hline Motive & $\begin{array}{c}\text { El Gouna } \\
(\boldsymbol{n = 1 5 1 )} \\
\text { Mean }\end{array}$ & SD \\
\hline Have fun & 4.74 & 0.59 \\
Meet Friends & 4.03 & 0.93 \\
Celebrating with Bride/Groom & 4.46 & 0.79 \\
Visit a new place & 3.23 & 1.19 \\
Experience the atmosphere & 4.26 & 0.81 \\
Eat and drink & 2.89 & 1.20 \\
Payed invitations & 3.50 & 1.02 \\
\hline
\end{tabular}

Table 4 Motivations for participating in a wedding at El Gouna

Results pointed to physical attributes of having a nice place to stay and price, along with the emotional attribute of romantic location being most important to wedding tourists. The majority of tourists chose El Gouna as it is an exotic wedding venue combining the 3'S', namely Sea, Sun and Sand, the splendid beaches and hospitable services, an amalgam of these elements evidently brings everlasting memories to the wedding experience. The features of the destination that forms part of the destination attributes accord to the overall satisfaction of the wedding trip experience, as seen in (table 5) where it scored a mean value of 4.27. The second major factor influencing decision to choose El Gouna which is the reasonable cost associated withthe wedding venues and scored a mean value of 3.49. Other determinants that encourage wedding tourism in El Gouna include the availability of services that El Gouna can offer as a wedding destination, the mean value was equal 3.49, arising a case described by homogeneity between the factors related to the set of wedding cost and the set of services availability such as hotels' facilities and service availability. The females were concerned about certain details such as the hair dressers; some foreigners require special type of cuisine; these are few examples witness during the empirical study. The processes of getting to the destination (flying time), which scored a mean value of 2.87 and ease of travel procedures with mean value 2.73 were least important factors.

\begin{tabular}{lcc}
\hline \multicolumn{1}{c}{$\begin{array}{c}\text { Factors } \\
\text { Descriptive Statistics }\end{array}$} & $\begin{array}{c}\text { El Gouna } \\
\text { Mean }\end{array}$ & $\begin{array}{c}\text { (n=151) } \\
\text { SD }\end{array}$ \\
\hline Geographical location (Exoticism) & 4.27 & 0.77 \\
Affordability of Wedding Venues & 3.49 & 1.05 \\
Special wedding offers and packages & 3.47 & 0.98 \\
Availability of personalized services such & 3.49 & 1.05 \\
catering services, decoration ... etc. & & \\
Getting to destination & 2.87 & 0.82 \\
Ease of travel Procedures & 2.73 & 0.99 \\
\hline
\end{tabular}

Table 5. Factors influencing decision for choosing El Gouna as the wedding destination

\subsection{Qualitative Analysis}

Analyzing the text and the transcribed narrative of the in-depth interviews, it seems that several motivations can drive couples and/or young ladies to celebrate or even plan to celebrate a destination wedding. The most common comments were as follows: 
An Egyptian couple 'Ayah and Amr' who already celebrated their wedding at El Gouna, and who are now in honeymoon agree that; 'selecting El Gouna for their wedding was an easy decision, starting by a celebration in the middle of the sea on a 'Catamaran', then the rehearsal celebration, followed by a simple wedding party with all important wedding favors such as floral decorations, photos, music and so on.

'Amira and Tamer', another couple, chose the beautiful 'La Maison Bleue' hotel in El Gouna just outside of Hurghada, for their wedding destination, having in mind the idea of getting rid of traditional weddings, with strict entertainment program, and concerned about not having a big party with "unknown" people who share this special moment with them.

John and Lisa from UK, used to visit different Egyptian destinations during their vacations, a quick response with a big smile that 'Gouna' would be their first choice getting ready for marriage. In this sense, other respondents also refer explicitly to the fact that celebrating a destination wedding is a way to experience more intimacy... They wanted to have their wedding special and without family stress.

An elder French couple, visiting El Gouna, stated that if they knew before about such a romantic and authentic place, they were probably decided to plan for their weddingthere. On the other hand, another French couple see that it would be much easier to get married in their home town, thinking about registry office, church etc., and then either spending their honeymoon in Egypt, choosing El Gouna as their targeting destination or opt for the part that starts about day 3 wedding ceremony.

A group of young Egyptian unmarried ladies, were very enthusiastic by the idea saying "Cheers for that... really we always dream to get married on the beach, to keep it all pretty and simple, but it would appear that it is going to be a long drawn out process".

A Russian-Egyptian couple who resident Hurghada, and chose El Gouna, as their wedding destination added 'We wanted to share the wedding experience with just a few people that we love and at the same time saving money, avoiding unnecessary showing-off behavior.

A group of young Egyptian female's friends, who were visiting El Gouna to attend their friend's wedding at 'Steigenberger Golf Resort', they were very excited by the ambience and the entourage for their friend's wedding, dressing all simple and casual, with flat shoes. Some of them, highlighted the idea that romantic moments like marriage proposals or love divulge/declaration, stimulated by a movie being filmed on a beach or a coast. They added 'Falling in love with the place and the setting creates the dream of the untraditional wedding destination'.

The unstructured interviews permitted a better understanding of the type of tourists that are attracted or would have been attracted to El Gouna as a wedding destination. It was clear from the stated results that most of the interviewees were seeking untraditional experiences, having in mind the idea of getting rid of traditional weddings, some of the them preferred rich and well planned wedding parties, giving great concern to caterers, wedding consultants, dresses, various beauty suppliers (hair, makeup), photographers, favors/bridesmaids gifts, music, honeymoon related, etc., on the other hand,others went more to the concept of simplicity.At the same time, it was clear that the majority see El Gouna as an affordable wedding destination. They are mostly attracted to 
places whereby their purchasing power is high through low cost of goods and services. Nevertheless, El Gouna as wedding destination also offers wide range of services that particularly attracts tourists to satisfying their wedding or honeymoon experience. Most of the respondents agreed upon the linking between the importance of the physical attributes related to the nature, location and ambience of the place, along with the emotional attribute of romantic occasions such as weddings and honeymoons.

\section{Limitations and Further Research Proposal}

Wedding travel is an important part of the tourism industry due to the changing socioeconomic factors. It is considered as a large industry in terms of money, but tracking where that money is spent or any other related figures, is difficult for several reasons. It is an industry that is made up of multiple smaller enterprises, and some of the individuals and businesses that provide services and products may only work part-time on wedding-related services to supplement their income or out of friendship, there will either be a minimal charge or no charge at all. Figures, if there are any, will likely not be in any "industry" tally. Meanwhile, many of the smaller components like caterers, DJs, and photographers, wedding favors, invitations, etc. also do other events without necessarily breaking their business down into wedding versus non-wedding (The Library of Congress, 2017).The current academic research was devoted to analyze the development of this relatively new and emerging trend of tourism which is still poor; hence, further studies aiming at investigating the wedding tourism phenomenon in Egypt are needed, adopting both a supply-side and demand-side perspective. Future studies may be tackling the study of the supply -side, focusing more on wedding's service providers and events' marketing responsible at weddings venues. Moreover, a larger sample would be more representative to other nationalities. And more innovative ideas can enrich the weddings market not only through typical beach weddings, but also by exploiting the cruise sector i.e. on-ship weddings.

\section{Implications and Conclusion}

Wedding tourism is a growing niche market that has impacted destinations all over the world. Over the past decade, Destination Weddings have evolved from a cost cutting trend to a booming market within the billion-dollar wedding industry.Statistics indicate that more than one out of every ten couples make the choice to say "I do" outside of their country of residence. Based on the said trend, the Weddings and Honeymoon market has been identified as an important niche market for many tourism destinations which could contribute significantly to the growth in visitor arrivals and expenditurewww.news.dm (February, 2013). With predicted demand continuing to increase, more innovative locations can open up more new opportunities for host destinations and thusservice providers are evolving. It is clear that Egypt with its variety of wedding destinations is affordable for most foreign travelers who wish and dream of a unique and untraditional wedding following by a honeymoon trip. Promoting Egypt as a wedding destination, is still in its infancy stage, and destinations' marketers still need to plan for this new market, selling the exotic appeal of Egypt as a wedding destination. With no doubt, the use of internet may help effectively in the distribution of such new tourism product to high potential markets,since most travelers are moving away from the traditional tour operators and travel agencies. 


\section{References}

Awaritefe,O.D.(2004). Destination image differences between prospective and actual tourists in Nigeria. Journal of Vacation Marketing, 10: 264-281.

Boden, S. (2001). "Superbrides": wedding consumer culture and the construction of bridal identity. Sociological research online, 6(1). Retrieved February 3, 2013 from http://www.socresonline.org.UK/6/1/boden.html.

Breg, J.R., (2013). “Now and Forever” Growth, Impacts and Future Evolution of Wedding Tourism.

Daniels, M., \& C. Loveless. (2007). Wedding Planning and Management. Oxford: Elsevier.

Del Chiappa,G. (2016). Wedding tourism. Encyclopedia of Tourism. Springer International Publishing.

Kim, S.S., \&Agrusa, J. (2005). The positioning of overseas honeymoon destinations. Annals of tourism research, 32(4), 887-904.

Kim, S., \&Prideaux, B. (2005). Marketing implications arising from a comparative study of international pleasure tourist motivations and other travel-related characteristics of visitors to Korea. Tourism Management, 26, 347-357.

Klenosky, D. B. (2002). The 'pull' of tourism destinations: A means-end investigation. Journal of Travel Research, 40, 385-395.

Major, B., McLeay, F. \&Waine, D. (2010). Perfect weddings abroad. Journal of Vacation Marketing 16 (3), 249-262.

March, R.G., \&Woodside, A.G., (2005). Tourism Behavior: Travelers' Decisions and Actions. Cambridge: CABI Publishing.

Prayag, G. \& Ryan C. (2011). The relationship between the 'push' and 'pull' factors of a tourist's destination: the role of nationality-an analytical qualitative research approach. Current Issues in Tourism .14(2):128-139.

Regev, D. (2017). "Egypt's tourism industry suffers a critical blow". [Online] DW. Retrieved 16 July 2017 Available from: http://www.dw.com/en/egypts-tourism-industry-suffers-a-critical-blow/a-39705321.[Accessed 30 November 2017].

Schumann, F.R, \&Amando, C., (2010). Japanese Overseas Weddings in Guam: A Case Study of Guam's First Hotel Wedding Chapel. South Asian Journal of Tourism and Heritage 3 (1), 173-181.

Travel Daily UK, 2013.Travel Daily Media. [Online] [Accessed 12 September 2017].

Travel Trends Today, 2014. ABTA Travel Trends Report. [Online] [Accessed 12 September 2017].

Travel Trends Today, 2016. ABTA Travel Trends Report. [Online] [Accessed 12 September 2017].

White, C. J., \& Thompson, M. (2009). Self-determination theory and the wine club attribute formation process. Annals of Tourism Research, 36(4), 561-586.

Yoon, Y., \&Uysal, M. (2005). An examination of the effects of motivation and satisfaction on destination loyalty: A structural model. Tourism Management, 26, 45-56.

https://www.google.com.eg/maps/search/el+gouna+map/27.6072905,32.2529114,7z [Accessed 20 September 2017]. https://www.news.dm/wedding-and-honeymmoon-stakeholders-briefing/ [Accessed 29 November 2017].

https://www.hotels.com/de1638584/hotels-el-gouna-egypt [ Accessed 06 December 2017].

https://www.madamasr.com/en/2016/07/13/news/economy/tourist-arrivals-to-egypt-down-by-half-in-may/ capmas/Central Agency for Public Mobilization and Statistics (CAPMAS) [Accessed 20 November 2017)

https://www.loc.gov/rr/business/wedding/The Library of Congress- wedding Industry Research -[ Accessed 02 December 2017] 